\title{
Araboplia lorisi new genus and species of Rutelinae from Saudi Arabia (Coleoptera, Scarabaeidae), with comments on the subtribe Popilliina
}

\author{
Marco ULIANA ${ }^{1, *} \&$ Guido SABATINELLI ${ }^{2}$ \\ ${ }^{1}$ Museo di Storia Naturale di Venezia, S. Croce 1730, 30135 Venice, Italy. \\ 2 493, route de la Fontaine, Le Grand Pré, villa 12, 01280 Prévessin, France. \\ *Corresponding author: marco.uliana.1@gmail.com; marco.uliana@fmcvenezia.it \\ 2Email: g.sabatinelli@hotmail.com \\ ${ }^{1}$ urn:1sid:zoobank.org:author:D5BE9B7E-F44F-4CE8-9BFA-1F498B0382D7 \\ ${ }^{2}$ urn:lsid:zoobank.org:author:48E45DD7-5660-43A5-BBA2-D67BDC825346
}

\begin{abstract}
Araboplia lorisi gen. et sp. nov. of Scarabaeidae Latreille, 1802 Rutelinae MacLeay, 1819, is described based on a single male specimen from the Arabian Peninsula, and compared with the closest Palaearctic genera. Araboplia gen. nov. is placed in the tribe Anomalini C.E. Blanchard, 1851 subtribe Popilliina Ohaus, 1918. This decision is due to its similarity with other Popilliina genera but lacks strong characters-based evidence, due to the poor definition of the Popilliina itself, which is discussed.
\end{abstract}

Keywords. Scarabaeoidea, Arabian Peninsula, new taxa, Anomalini, Popilliina.

Uliana M. \& Sabatinelli G. 2017. Araboplia lorisi new genus and species of Rutelinae from Saudi Arabia (Coleoptera, Scarabaeidae), with comments on the subtribe Popilliina. European Journal of Taxonomy 373: 1-12. https://doi.org/10.5852/ejt.2017.373

\section{Introduction}

Among the unidentified Scarabaeidae of the Arabian peninsula received for study from the Naturhistorisches Museum Basel (Switzerland) by GS, we identified a single specimen of Rutelinae that cannot be referred to any known species or genus.

In the present paper we describe this taxon as Araboplia lorisi gen. et sp. nov., and compare it with the most similar genera. Araboplia gen. nov. is tentatively placed within the subtribe Popilliina Ohaus, 1918 , the weak definition of which is discussed.

\section{Material and methods}

\section{Specimen treatment}

The specimen studied, originally greasy, was soaked for several days in a solution of $50 \%$ water and $50 \%$ acetone, in order to clean and degrease it and recover the original appearance of its dense vestiture. The hairs were then gently dabbed with blotting paper and raised with a soft brush before complete drying. The aedeagus was extracted and mounted dry on a card pinned under the specimen. 


\section{Image production}

All-in-focus images were produced after stacks of about 40-80 photos taken with a Canon EOS 600D camera and a Canon MP E-65 lens, moved through Cognysys StackShot system. The original photographs were mounted with CombineZP software and the resulting image was enhanced with Photoshop CS6 software.

\section{Acronyms of collections}

GS $=$ coll. Guido Sabatinelli, Prevessin, France

$\mathrm{MU}=$ coll. Marco Uliana, Codevigo, Italy

MSNG = Museo Civico di Storia Naturale G. Doria, Genova, Italy

NMP $=$ National Museum, Prague, Czech Republic

NHMB $=$ Naturhistorisches Museum Basel, Switzerland

\section{Data treatment}

Citations of data from labels of specimens are standardized as for the arrangement of information and the format of date. Localities are reported verbatim. Explanatory interpretations of original data are added in square brackets.

\section{Material examined}

The holotype of Araboplia lorisi gen. et sp. nov. was compared with the specimens of Palaearctic Popilliina listed below, which include the type species of all genera occurring in the Western Palaearctic. We also directly examined the Afrotropical species Trichopopillia dorsalis (Kraatz, 1892) (as T. dorsalis subspecies nilotica (Kraatz, 1892) occurs in southern Egypt) and Gnatholabis ugandana Ohaus 1913, as a representative of the genus in which $T$. dorsalis was originally placed.

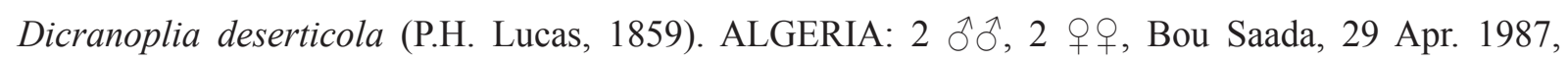
G. Magnani leg. (GS, MU).

Gnatholabis ugandana Ohaus, 1913. UGANDA: 3 ふૂર, Kabulamuliro, 1910, Dr. E. Bayon [leg.], det. E. Benderitter 1927 (MSNG).

Pharaonus (Pharaonus) adelphus Keith, Sabatinelli \& Uliana, 2015. IRAN: 1 O, paratype, Kerman, 2 Apr. [19]51, Salavatian leg. (MU).

Pharaonus (Pharaonus) caucasicus (Reitter, 1888). ARMENIA: 2 $\widehat{\jmath}$, Armenian SSR, Vedi, 19 Jun. 1982, Kalashjan leg. (GS); 1 J , Vedi distr., Gorovan Sands, 22 Jun. 1992, I. Osipov vendit (GS);

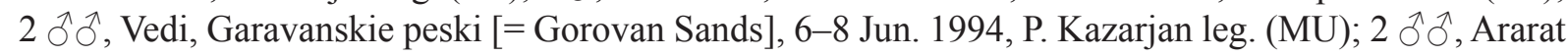
prov., Goravan village subr., semi-desert, 3-8 Jun. 2013, T. Ghrejyan leg. (MU); 1 §, Vedi, Gorovan 17-20 Jun. 2013, Skoupy leg. (MU).

Pharaonus (Pharaonus) fasciculatus (Burmeister, 1844). LIBYA: $2 \hat{\jmath}$, Trip. [Tripolitania], Sirte, 21 May 1936, R.e C. Koch leg. (MU). - EGYPT: 1 ठ, Kirdassah [=Kirdasah], 6 May [19]33, W. Wittmer leg. (MU).

Pharaonus (Pharaonus) saharicus Král, 2012. ALGERIA: 1 đે, paratype, Tamrit, Tassili n'Ajjer, 1700 m, 6-8 May 1987 (NMP).

Pharaonus (Pharaonus) varicoloreus (Burmeister, 1844). TURKEY: 1 q, Adiyaman, Halfeti, Birecik, 20 May 1998, Snizek leg. (MU). - IRAN: 2 ô ô, Zagros Mt., prov. Fars, Shiraz-Guyom eoj., 6 Jun. 2011, J. Dalihod leg. (MU). - SYRIA: 3 ふふર, environs of Palymra, 25 May 2009, M. Šárovec leg. (MU). 
Pharaonus (Tamerlanius) lederi (Reitter, 1888). UZBEKISTAN: 1 §,, Buchara, Koron $15 \mathrm{~km}$ from Ekoc.

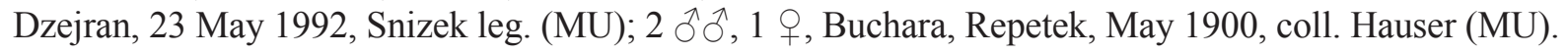

Pharaonus (Tamerlanius) semenowi (Reitter, 1887). UZBEKISTAN: $1 \hat{\jmath}$, Kul'dzhuktau, Kizilkum desert, Haloxylon (saxaul) in the sand, 15 May 1961, Dlusskij leg. (MU). - TAJIKISTAN: $2 \hat{\jmath}$, near Schaartuz [=Shahrtuz], Dzharkurgan env., 7 Apr. 2007, O. Pak leg. (MU).

Pseudoblitopertha inexpectata Keith, 2000: examination based on unpublished photos of the holotype provided by Denis Keith.

Tribopertha aegyptiaca (C.É. Blanchard, 1851). ALGERIA: 1 đૈ, south of Bou Sàada, 1875, R. Oberthur leg. (GS); $10 \widehat{\partial} \widehat{\partial}, 2$ 우, Bou Saada, 7 Apr. 1981, Pierotti leg. (MU). - TUNISIA: $2 \widehat{\jmath} \widehat{\partial}, 2$ 우, Kasserine, Magel Bel Abbes (Feriana-Gafsa), 30 Mar. 2013 G. Sabatinelli leg. (MU). - ISRAEL: 2 ๙ Netanya (city, south), 17 Mar. 2016, G. Wizen leg. (MU).

Trichopopillia dorsalis (Kraatz, 1892). "AFRICA EQUAT. [= SOUTH SUDAN]": 1 §,, syntypus,

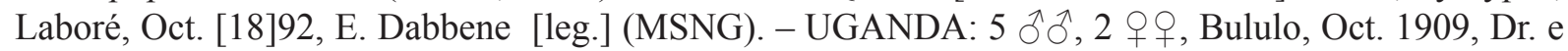

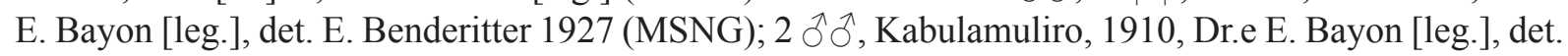
E. Benderitter 1927 (MSNG).

Observations on the characterization of the subtribe Popilliina are also based on the examination of the following species of Anomalina Streubel, 1839, the abundant material of which is summarised (all in coll. MU):

Blitopertha nigripennis (Reitter, 1888): 102 specimens of both sexes from TURKEY (different localities in the provinces of Isparta, Antalya, Kirsehir, Mersin, Sivas, Erzurm, Bingol, Hatay); IRAN (provinces of Golestan and Zanjan); SYRIA(Qal'at al Hisn; Djebel el-Druze); LEBANON (Laqlouq) and JORDAN (Zubya Nat. Park).

Blitopertha lineolata lineolata (Fischer von Waldheim, 1824): 65 specimens of both sexes from GREECE (different localities in the provinces of West Macedonia, East Macedonia, Thessaly, Peloponnese, Crete id., Kos id.) and TURKEY (different localities in the provinces of Izmir, Aydin, Isparta, Ankara, Nevsehir, Çankiri).

Blitopertha lineata (Fabricius, 1798): 32 specimens of both sexes from MOROCCO (different localities in the regions of Souss-Massa, Marrakech-Safi, Rabat-Salé-Kenitra, Fes-Meknès).

Exomala (Taxipertha) conspurcata (Harold, 1878): 32 specimens of both sexes from RUSSIA (Khasan reg., Vitjaz Bukhta) and JAPAN (Osaka, Tondabayashi).

Phyllopertha horticola (Linnaeus, 1758): 74 specimens of both sexes from GERMANY (Gossenhain); AUSTRIA (Kaprum); ITALY (different localities in the regions of Lombardia, Trentino Alto Adige, Friuli Venezia Giulia, Veneto); ROMANIA (Hunedoara); ESTONIA (Palupohja; Saaremaa id.) and RUSSIA (Vladivostok).

Phyllopertha irregularis C.O. Waterhouse, 1875: JAPAN: 4 $ぇ ึ, 1$, , Nagano prov., Oshiha. 


\section{Results}

Class Hexapoda Blainville, 1816

Order Coleoptera Linnaeus, 1758

Family Scarabaeidae Latreille, 1802

Subfamily Rutelinae Macleay, 1819

Tribe Anomalini Streubel, 1839

Subtribe Popilliina Ohaus, 1918

Araboplia gen. nov.

urn:1sid:zoobank.org:act:BE8189F2-2044-4EB2-BAE8-43C00824B437

\section{Type species}

Araboplia lorisi gen. et sp. nov.

\section{Differential diagnosis}

Within Popilliina, it is most close to the genus Dicranoplia Reitter, 1903, from which it is distinct by the following characters states (on male): clypeus simple, not raised; peculiar shape of the anterior claw; spur of the anterior tibia short and blunt.

\section{Description}

Clypeus with anterior margin regular, poorly raised from lateral margins, not sinuate or notched in the middle.

Basal margin of pronotum broadly rounded, with the three-segmented partition typical of Popilliina (median part appearing truncate) almost imperceptible.

Elytra narrow, flattened, with maximum width just below the humeral region, then narrowing towards the apex. In dorsal view, the lateral margin is completely visible and straight in its medial part. In lateral view, the lateral margin is strongly sinuate, protruding in a large sub-humeral lobe and retreating in a broad concavity until the apical round.

Fore legs: tibia with two well-developed apical teeth, the position of the third tooth is marked by a hardly noticeable knob, apical tooth acute but with blunt apex, proximal tooth obtuse, both non-spiniform; apical spur vestigial, not visible from above as almost non-emerging from its socket; internal claw broader than the external one, asymmetrically separated at the apex, the internal margin bearing a broad and low expansion defining a deep and narrow basal notch, external claw simple. Mid legs: external claw separated at the apex, longer and much more curved than the internal one, which is not separated. Posterior legs: tibia enlarged from the base to the apex, not sinuated, with two lateral carinae; the proximal carina vestigial, placed at about mid length, only developed near the dorsal edge, and bearing 4-5 long setae, thick but not spiniform; the distal carina complete (covering the whole width of the tibia), placed near the apex, at about $5 / 6$ of the whole length, and bearing short spiniform setae; both claws not separated, the external larger than the other but similar in shape.

\section{Etymology}

The name of the genus is derived from the area of occurrence of the species (the Arabian Peninsula) and the suffix -oplia, for assonance with other genera of Rutelinae including Dicranoplia Reitter, 1903, the closest genus. 
Araboplia lorisi gen. et sp. nov.

urn:1sid:zoobank.org:act:15AF1535-9CC8-44A4-A6DA-FCBF9B869739

\section{Diagnosis}

Figs $1-9,14$

Same as for genus.

\section{Etymology}

The specific epithet is dedicated by MU to his father, Loris Uliana, with thanks for his constant encouragement and support of his interest in natural sciences and love for insects during the years of his youth. In addition, the two subjects are alike in being covered with white hairs.

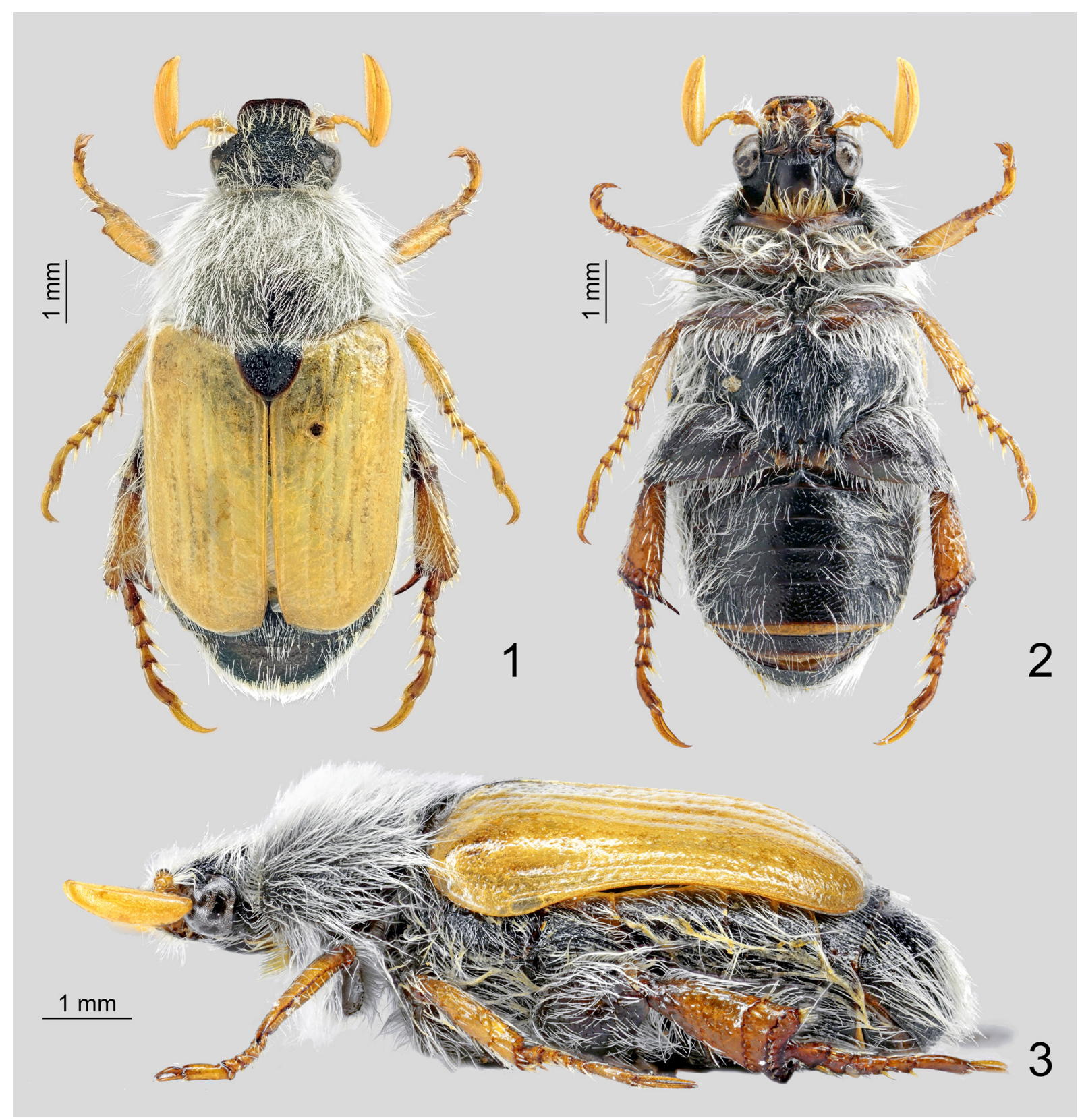

Figs 1-3. Araboplia lorisi gen. et sp. nov., habitus. 1. Dorsal view. 2. Ventral view. 3. Lateral view. 

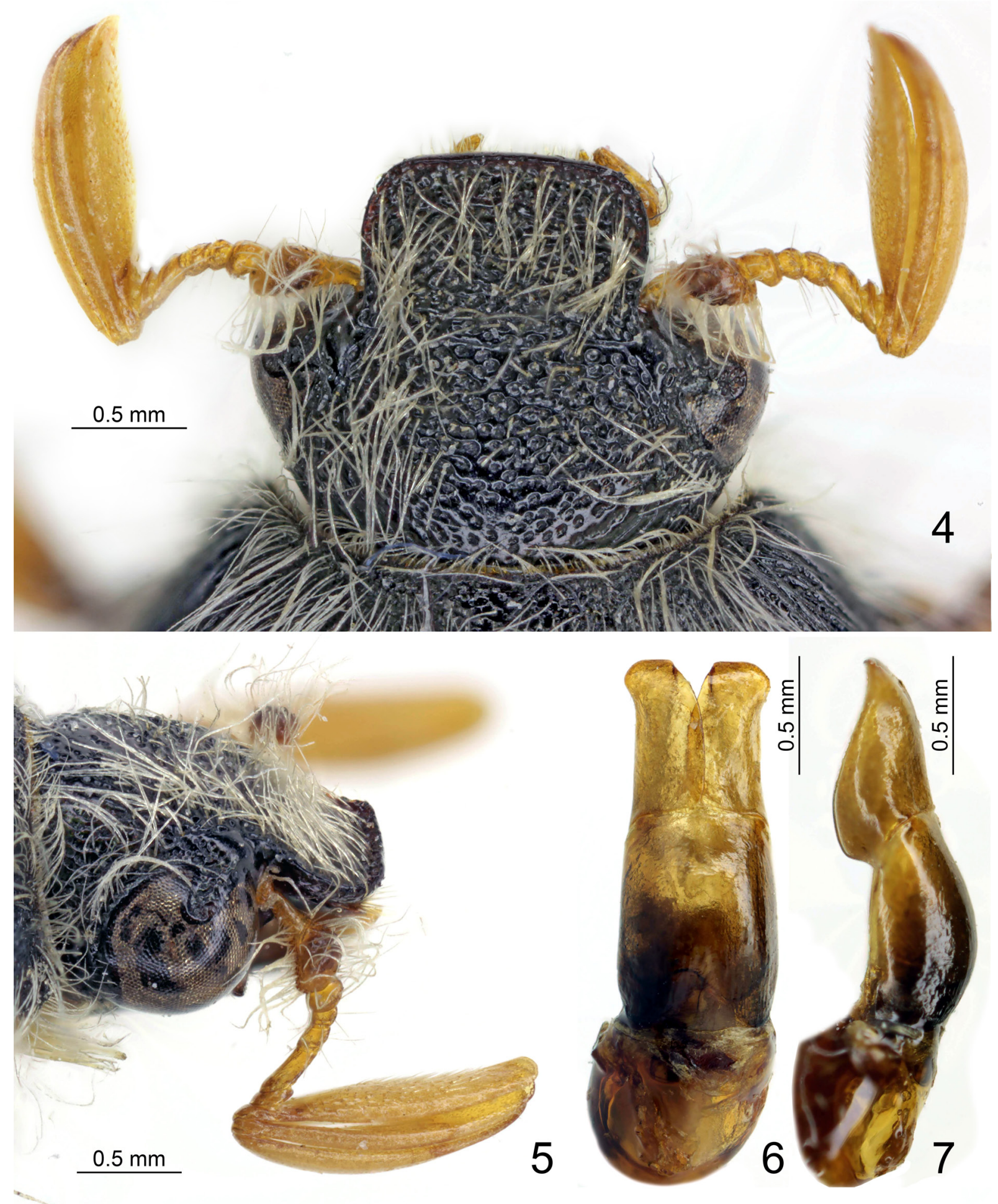

Figs 4-7. Araboplia lorisi gen. et sp. nov., ${ }^{\lambda}$, holotype, anatomical details. 4. Head in dorsal view. 5. Head in oblique lateral view. 6. Aedeagus in dorsal view. 7. Aedeagus in lateral view. 


\section{Material examined}

\section{Holotype}

SAUDI ARABIA: 1 ð, near Ar Riyad, 1989, [Ex] Collection David Král Praha (NHMB).

\section{Description}

Characters mentioned in the diagnosis and the description of the genus are not repeated.
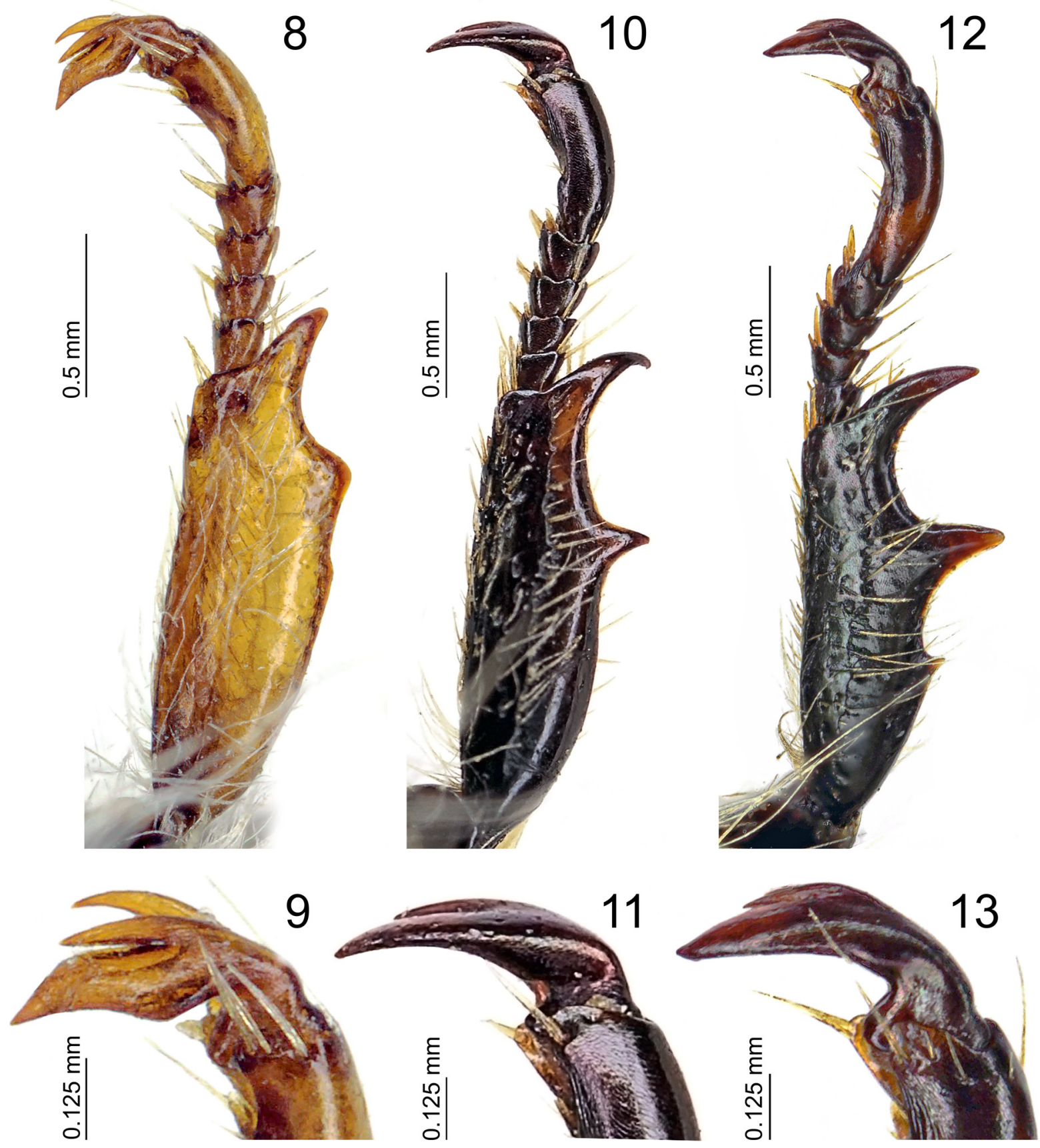

Figs 8-13. Right forelegs (above) and detail of their claw (below). 8-9. Araboplia lorisi gen. et sp. nov. 10-11. Tribopertha aegyptiaca (C.É. Blanchard, 1851). 12-13. Dicranoplia deserticola (P.H. Lucas, 1859). 


\section{Colour of integument}

Body black, shining, without coloured metallic reflections. Abdominal sternites dark brown. Elytra uniformly pale yellow. Appendages rusty orange except the apex of the first antennal article, the anterior and the median femora, which are slightly darkened, and the posterior femora, which are dark brown.

\section{Vestiture}

The whole body, especially the head and pronotum, are densely covered with long, fine white hair-like setae, except tibia (fine setae present, but sparse and mixed with spiniform setae), tarsi (only spiniform setae are present), antennal articles 5-10 (only short sensillar setae are present on antennal club), scutellum (bearing few short hairs), and elytra (glabrous).

\section{Morphology}

HEAD. Coarsely and densely punctate, punctures confluent and producing irregular transverse wrinkles on the clypeus, less densely confluent and not forming transverse wrinkles on the rest of the head.

Pronotum. Densely punctured, punctures much finer than those of the head, confluent, well impressed along their anterior border, evanescent along the posterior one. Punctures evenly distributed except for a very narrow, poorly defined, medial stripe extending along the basal third. Lateral sides of pronotum finely bordered, base bordered except in front of the scutellum.

ELYTRA. Leaving the propygidium uncovered for about half of its length. Each elytron with seven recognizable striations, all punctate. Striations 1-4 well impressed along their whole length, 5 very weak, only visible in its distal portion, 6-7 well impressed only in the basal portion. Intervals with sparse weak punctures, the whole surface with smooth and irregular transverse corrugations.

EPIPLEURA. Poorly separated from the rest of the elytron, enlarged and faintly swollen at the sub-humeral lobe, narrow on the rest of its length, progressively fading in the apical part. Epipleural membrane present only in the apical quarter. A tiny spine present at the sutural angle of each elytron. Pygidium gibbose, with a strongly protruding convexity, covered with dense, sharp and evenly distributed punctures.

ANTENNA. 9-segmented, article 5, measured along its posterior border, about as long as articles 3-4. Club about $1.4 \times$ as long as the rest of the antenna.

LEGS. Medial legs normally developed, posterior legs comparatively much broader, in particular the tibia, which is about $1.8 \times$ as long as wide (maximum width at the distal end) and about $3.4 \times$ the maximum width of the median tibia. Apex of posterior tibia pitted with 13-14 large, deep sockets, hosting spiniform setae similar to those of the apical carina.

PARAMERES. As in Figs 6-7.

\section{Discussion}

\section{Classification within subtribe Popilliina}

According to the systematic arrangement by Machatschke $(1957,1972)$ Araboplia gen. nov. should be included in the tribe Anomalini Streubel, 1839, based on the nine-segmented antennae and the presence of the epipleural membrane on elytra (Arrow 1917; Ohaus 1934; Machatschke 1957). Within Anomalini, the morphological similarity with the genera Dicranoplia Reitter, 1903, Pharaonus C.É. Blanchard, 1851 and Tribopertha Reitter, 1903 suggests the placement of Araboplia gen. nov. within the subtribe Popilliina. Character-based evidence for this placement is not strong, but this is due to the weak definition of the Popilliina itself. 
In fact, as pointed out by Jameson et al. (2007), many suprageneric taxa of Rutelinae lack a clearcut character-based definition, and this is the case for Popilliina too. The subtribe Popilliina was established by Ohaus (1918) by listing the taxa included; no diagnosis, however, was provided. Later, Machatschke (1957) proposed a key to the subtribes of Anomalini where two characters were used to separate Popilliina from Anomalina: the shape of the basal margin of the pronotum (regularly rounded in Anomalina vs shaped in three segments by a median truncation or notch in the Popilliina) and the shape of the body (dorsally more convex in the Anomalina vs more flat in the Popilliina). Although the two alternative states of the pronotum have been clearly defined by the author, such a clear-cut definition does not correspond with the actual diversity. Members of the Anomalina with the base of the pronotum looking at least in part "three-segmented" due to a straight base and/or lateral sinuations exist (e.g., Exomala conspurcata (Harold, 1878), Phyllopertha horticola (Linnaeus, 1758)), as well as members of the Popilliina having a pronotal base where the "three-segmented" shape is almost unrecognizable, such as species in the genera Gnatholabis Erichson, 1847 (e.g., G. ugandana Ohaus, 1913), Pharaonus (e.g., Ph. saharicus Král, 2012), Tribopertha (e.g., T. aegyptiaca (C.É. Blanchard, 1851)). It should be noted that Baraud, in his key to the genera of Rutelinae of North Africa (Baraud 1985: 513), redefined the pronotal condition of the three genera of the Popilliina occurring there (Dicranoplia, Pharaonus and Tribopertha), as having the base of the pronotum forming an arched concavity, a definition which is, however, no more suitable than the previous one, since it does not apply unambiguously to all species. The second character considered by Machatschke in the definition of Popilliina, related to body convexity, is even weaker and liable to subjective interpretation, since the convexity of body lacks clear cut definitions and is broadly overlapping. For example, members of the genera Blitopertha Reitter, 1903 and Phyllopertha Stephens, 1830 (Anomalina) are not noticeably more convex than those of Dicranoplia, Pharaonus or Tribopertha (Popilliina).

In addition to the poor morphological definition outlined above, it should be remarked that monophyly of the Popilliina has never been tested. Consequently, it should be considered that the Popilliina may be found to be a non-natural group, as happened with Anisopliina, according to the phylogeny produced by Jameson et al. (2007).

As a phylogenetic analysis or a re-assessment of the Popilliina are far beyond the scope of this work, we place Araboplia gen. nov. in the Popilliina based on its morphological similarity to the aforementioned Euro-Mediterranean genera placed in this subtribe.

\section{Distinction from other genera}

Araboplia gen. nov. shares a strong habitus similarity with three other genera of Popilliina inhabiting desert or subdesert areas of the Mediterranean region, namely Dicranoplia, Pharaonus and Tribopertha, due to the combination of dark integument lacking strong metallic colours, elytra mostly or completely testaceous, and dense vestiture of hair-like setae at least on the ventral side. On the other hand, there is no obvious affinity with the only other genus of Popilliina occurring in the Western Palaearctic (Pseudoblitopertha Keith, 2000, from south-eastern Turkey) nor with those from the Eastern Palaearctic. No match or similarity of habitus was found among the Rutelinae of the Ethiopic fauna either, including the genus Trichopopillia Ohaus, 1897, one species of which is recorded in the Saharan transition region of Egypt (T. dorsalis nilotica (Kraatz, 1892), see Machatschke 1972 and Baraud 1985), and the genus Gnatholabis Erichson, 1847, to which T. dorsalis was originally assigned.

The distinction of Araboplia gen. nov. from Dicranoplia and Tribopertha, both inhabiting desert areas of North Africa, is easily done based on the morphology of the teeth of the forelegs (cf. Figs 8, 10, 12), which provides a straightforward diagnostic character. The distinction from Pharaonus, widespread in North Africa and the Middle East, is easily done based on the external claw of the mid legs, which is bifid in Araboplia gen. nov. and simple in Pharaonus, and on the morphology of the posterior tibia. 

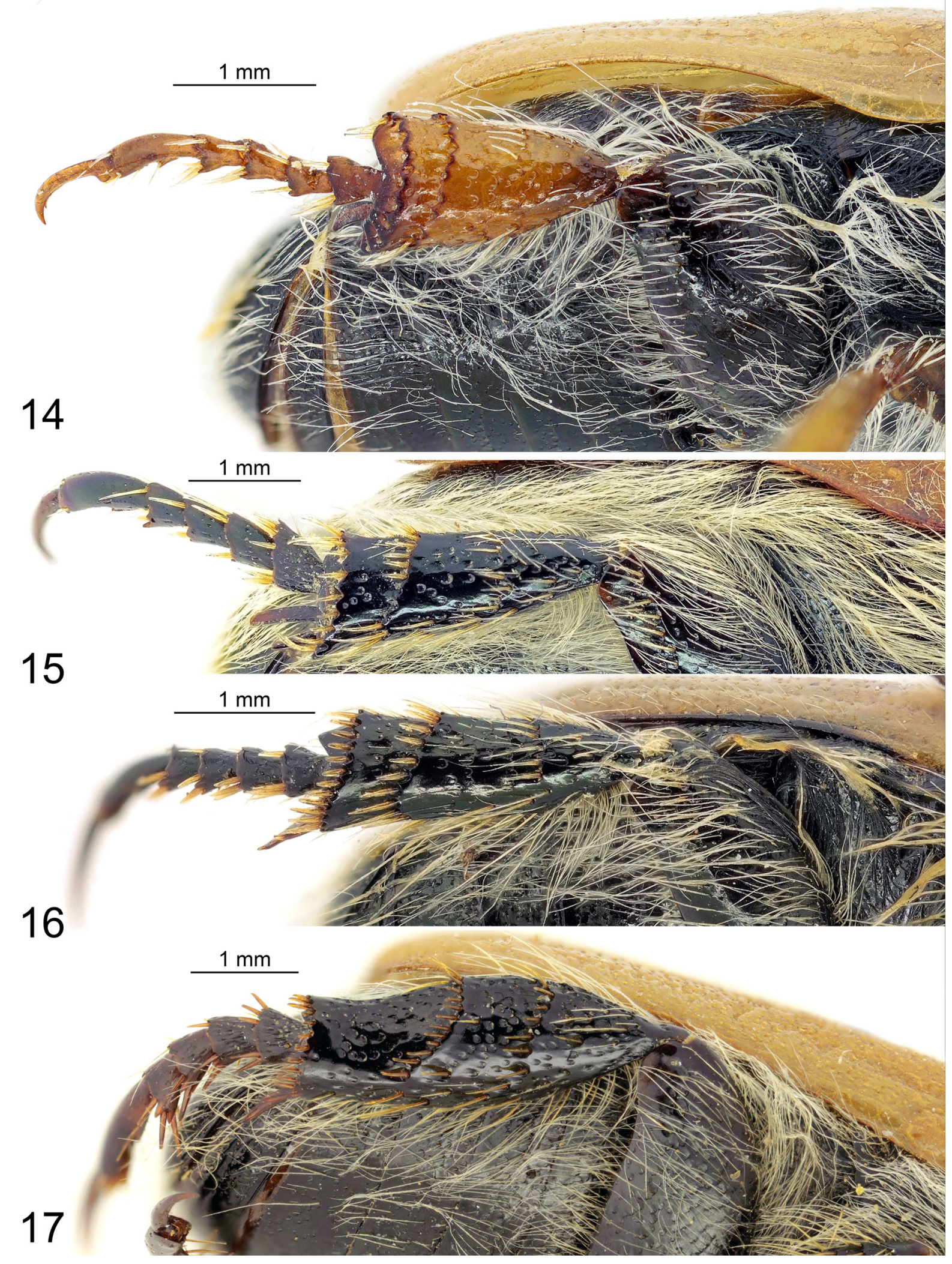

Figs 14-17. Comparative presentation of the posterior tibia in latero-ventral view. 14. Araboplia lorisi gen. et sp. nov. 15. Dicranoplia deserticola (P.H. Lucas, 1859). 16. Tribopertha aegyptiaca (C.É. Blanchard, 1851). 17. Pharaonus fasciculatus (Burmeister, 1844). 
Table 1. Summary of states of diagnostic characters in males of Araboplia gen. nov. and the three closest genera.

\begin{tabular}{|l|c|c|c|c|}
\cline { 2 - 5 } \multicolumn{1}{c|}{} & Araboplia & Dicranoplia & Pharaonus & Tribopertha \\
\hline Clypeus: fore margin more raised than sides & no & yes & no & yes \\
\hline Elytra: flattened and laterally sinuated & yes & yes & no & no \\
\hline Larger fore claw: shape of internal margin & angled, protruding & regular & regular & regular \\
\hline Spur of anterior tibia & vestigial & vestigial & normal & absent \\
\hline Well-developed teeth on anterior tibia & 2 & 2 & $2-3$ & $2-3$ \\
\hline Teeth of anterior tibia: shape & blunt & spine-like & blunt & spine-like \\
\hline Main claw of middle leg: shape & bifid & bifid & simple & bifid \\
\hline Posterior tibiae: whether strongly enlarged & yes & yes/no & no & no \\
\hline Posterior tibiae: shape & conical & conical & sinuated & conical \\
\hline
\end{tabular}

In Araboplia gen. nov. the latter is not sinuate, and has its maximum width at the distal end (vs sinuated, with maximum width in the basal half in Pharaonus) and has the distal carina close to the apex, at 5/6 of the whole length (vs carina at about $3 / 5$ of the length in Pharaonus) (cf. Figs 14, 17).

Additional diagnostic characters are found in the morphology of the clypeus, the shape of the elytra, the development of the anterior tibial spur, the shape of the anterior internal claw and the enlargement of the posterior tibia.

The clypeus of Araboplia gen. nov. is simple, with the anterior margin just slightly and gently raised in continuity with the lateral margins (Figs 4-5): this condition is close to that of Pharaonus (Pharaonus), but is very different from that of Tribopertha and Dicranoplia. It should be noted that, although Baraud (1985: 513) keyed Tribopertha as having a "simple" clypeus (i.e., regularly rounded, not raised), the anterior margin is actually distinctly raised upwards in respect to the lateral margins, especially at the anterior angles, being therefore similar to the more abruptly raised clypeus of Dicranoplia.

Elytra of Araboplia gen. nov. are flattened, with the lateral margin straight in dorsal view and deeply concave in lateral view, whereas they are normally convex, with the lateral margin rounded in dorsal view and quite straight in lateral view, in Pharaonus and Tribopertha.

The tibial spur of the anterior legs is vestigial in Araboplia gen. nov. and almost invisible in dorsal view, therefore evidently different from that normally developed spur of Pharaonus. The spur is also present, although very small, in Dicranoplia (contrary to the diagnosis given by Baraud 1985: 526), while it appears to be actually absent in Tribopertha.

The claw of the forelegs has a broad and low angled protrusion at about mid length of the internal margin, which is not found in the other genera (Figs 9, 11, 13).

The posterior tibiae (Figs 14-17) are very enlarged in Araboplia gen. nov., and therefore well different from those of Pharaonus and Tribopertha. According to its original description and drawings, Dicranoplia demoflysi Baraud, 1989 (not directly examined by us) shares a similar condition, while the only other species of Dicranoplia has less enlarged tibiae (Fig. 15).

The states of the diagnostic characters in Araboplia and the three most similar genera are summarized in Table 1. 


\section{Acknowledgements}

We are grateful to Denis Keith (Muséum des Sciences Naturelles et de Préhistoire, Chartres) for sending us pictures of Pseudoblitopertha, to David Kral (Charles University, Prague), for lending us a paratype of Pharaonus saharicus, to Pol Limbourg (Institut Royal des Sciences Naturelles de Belgique, Brussels) for preliminary comments on Araboplia gen. nov., to Michel Brancucci ( $\dagger$ ) (Naturhistorisches Museum Basel) for entrusting us this interesting specimen, to Roberto Poggi (Museo Civico di Storia Naturale di Genova), for lending us specimens of Gnatholabis and Trichopopillia. Max Barclay (Natural History Museum, London) and two anonymous referees improved contents and language of the manuscript.

\section{References}

Arrow G.J. 1917. The Fauna of British India, Including Ceylon and Burma. Coleoptera Lamellicornia part II (Rutelinae, Desmonycinae, and Euchirinae). Taylor \& Francis, London.

Baraud J. 1985. Coléoptères Scarabaeoidea. Faune du Nord de l'Afrique du Maroc au Sinaï. Editions Lechevalier, Paris. Encyclopédie Entomologique.

Jameson M.L., Micó E. \& Galante E. 2007. Evolution and phylogeny of the scarab subtribe Anisopliina (Coleoptera: Scarabaeidae: Rutelinae: Anomalini). Systematic Entomology 32 (3): 429-449.

Machatschke J.W. 1957. Coleoptera Lamellicornia Fam. Scarabaeidae Subfam. Rutelinae. Tribus Anomalini. Zweiter Teil. In: Wytsman P.A.G. (ed.) Genera insectorum. Fascicule 199 (B). DesmetVerteneuil, Bruxelles.

Machatschke J.W. 1972. Superfamilie Scarabaeoidea, Familie Melolonthidae, Subfamilie Rutelinae. In: Junk W. \& Schenkling S. (eds) Coleopterorum catalogus. Supplementa. Pars 66. Fasc. I. Junk, Berlin.

Ohaus F. 1918. Scarabaeidae: Euchirinae, Phaenomerinae, Rutelinae. In: Junk W. \& Schenkling S. (eds) Coleopterorum Catalogus. Vol. XX. Scarabaeidae II. Pars 66. Junk, Berlin.

Ohaus F. 1934. Coleoptera Lamellicornia. Fam. Scarabaeidae. Subfam. Rutelinae. In: Wytsman P.A.G. (ed.) Genera insectorum. Fasc. 199 (A). Desmet-Verteneuil, Bruxelles.

Manuscript received: 9 May 2017

Manuscript accepted: 12 September 2017

Published on: 1 December 2017

Topic editor: Gavin Broad

Section editor: Max Barclay

Desk editor: Kristiaan Hoedemakers

Printed versions of all papers are also deposited in the libraries of the institutes that are members of the EJT consortium: Muséum national d'Histoire naturelle, Paris, France; Botanic Garden Meise, Belgium; Royal Museum for Central Africa, Tervuren, Belgium; Natural History Museum, London, United Kingdom; Royal Belgian Institute of Natural Sciences, Brussels, Belgium; Natural History Museum of Denmark, Copenhagen, Denmark; Naturalis Biodiversity Center, Leiden, the Netherlands; Museo Nacional de Ciencias Naturales-CSIC, Madrid, Spain; Real Jardín Botánico de Madrid CSIC, Spain. 